\title{
Sequestration of Heavy Metals From Coal Wash Water Using Biochar From Pyrolysis of Morula Shells
}

\author{
Lame Elsie Othugile ${ }^{1}$, Tumeletso Lekgoba ${ }^{1 *}$, Freeman Ntuli ${ }^{1,2}$
}

\begin{abstract}
${ }^{1}$ Department of Chemical, Materials and Metallurgical Engineering, Botswana International University of Science and Technology, Palapye, BOTSWANA ${ }^{2}$ Department of Chemical Engineering Technology, University of Johannesburg, Doornfontein, Johannesburg, SOUTH AFRICA

*Corresponding Author: lekgobat@biust.ac.bw
\end{abstract}

Citation: Othugile, L. E., Lekgoba, T. and Ntuli, F. (2022). Sequestration of Heavy Metals From Coal Wash Water Using Biochar From Pyrolysis of Morula Shells. European Journal of Sustainable Development Research, 6(1), em0173. https://doi.org/10.21601/ejosdr/11377

ARTICLE INFO

Received: 30 Jun. 2021

Accepted: 2 Oct. 2021

\begin{abstract}
Biomass is a source of low-cost adsorbents used in the removal of contaminants. In this study, shells from an indigenous tree in Southern Africa called Morula were pyrolyzed to produce biochar that was used to sequester heavy metals from coal wash water. The produced biochar was activated using hydrochloric acid ( $\mathrm{HCl})$ and parameters such as the cation exchange capacity (CEC), point of zero charge (pHzc), elemental composition, mineral composition, proximate analysis and surface functional groups were determined. Batch adsorption experiments were carried out at $150 \mathrm{rpm}$ for $60 \mathrm{~min}$ and $25^{\circ} \mathrm{C}$ at different metal ion concentrations and adsorbent dosages. The metal ions of interest were $\mathrm{Zn}, \mathrm{Ni}$ and $\mathrm{Fe}$ and it was found that $\mathrm{Fe}$ recorded higher removals for both raw and activated biochar. Generally higher removals were noticed for both raw and activated at lower dosages $(0.2-1.0 \mathrm{~g} / 100 \mathrm{~mL})$ and lower metal ion concentration (between 40 and $60 \mathrm{ppm}$ ) while lower removals were found at higher dosages $(1-5 \mathrm{~g} / 100 \mathrm{~mL}$ ) and higher metal ion concentrations (between $400-600 \mathrm{ppm}$ ).
\end{abstract}

Keywords: adsorption, biochar, coal wash water, Morula Shells, sequestration

\section{INTRODUCTION}

Water pollution is a serious global issue which adversely affects our lives and studies show that it is expected to worsen in the coming decades (Ali and Gupta, 2007). Over the years, the main source of health concerns in water has been microbial contaminants. But with time, it was discovered that chemical contaminants also contribute to pollution of water sources after discovery of analytical methods to measure these contaminants (Sharma and Bhattacharya, 2017). These include anionic substances (nitrates, sulphates, chlorides, fluorides and phosphates), toxic metals including heavy metals and organics such as pesticides, herbicides, fungicides and insecticides together with dyes and hydrocarbons (Sen and Gomez, 2011). These contaminants are contained in effluents from different industrial activities such as manufacture of cosmetics, pharmaceuticals, fertilisers, food, textiles, steel and mining industries (Cao et al., 2019). Among these pollutants, heavy metals such as $\mathrm{Fe}, \mathrm{Cu}, \mathrm{Cd}, \mathrm{Pb}, \mathrm{Co}, \mathrm{Ni}, \mathrm{Hg}$ and As are classified as harmful due to their toxicity to the environment and non-biodegradability and their presence in water causes bioaccumulation in living organisms. Even though some are essential for micronutrients in the soil from underground water, some cause damage to the nervous system and internal organs in human beings if found in certain concentrations in potable water (Abdullah, 2013). The further increase in population growth, industrialization, domestic, mining and agricultural activities worsen the situation. In response to this, treatment technologies such as ion exchange, chemical precipitation, adsorption and membrane technologies have been developed by these industries to treat wastewater prior to its disposal to the environment (Malaviya and Singh, 2011). Research on adsorption was unearthed by the desire to achieve zero pollution and a green technology as it was identified as environmentally friendly due to application of clean adsorbent materials especially biochars.

The aim of this research was to utilize biochar produced from the pyrolysis of morula shells at $600^{\circ} \mathrm{C}$ to sequester heavy metal ions from aqueous solutions. Morula (Sclerocarya Birrea) is a naturally occurring fruit tree found in abundance in Southern African countries such as Botswana, Zimbabwe, Zambia, Namibia and South Africa (Wynberg et al., 2014). Even though this is a seasonal fruit, the shells are readily available throughout the year and often disposed as waste material and hence its recent consideration for use as a low-cost adsorbent. The present study involved investigating the effect of both raw and modified biochar on the removal of $\mathrm{Zn}, \mathrm{Ni}$ and Fe from aqueous solutions. 


\section{MATERIALS AND METHODS}

\section{Materials}

Wastewater collected from a local coal mine was used for this study. A dilution ratio of 1:10 with distilled water was used to prepare the lower ion concentration wastewater with the objective of understanding the behaviour of the biochar when metal ion concentrations are reduced. The samples were then acidified with small amount of nitric acid to preserve the water samples from forming metal compounds. Morula shells were collected from a nearby tree and pyrolyzed using a batch pyrolysis pilot plant. $2 \mathrm{M} \mathrm{HCL}$ was used to activate the biochar produced. Sodium acetate $\left(\mathrm{NaCH}_{3} \mathrm{CO}_{2}\right)$, ammonium acetate $\left(\mathrm{NH}_{4} \mathrm{CH}_{3} \mathrm{CO}_{2}\right)$ and ethanol $\left(\mathrm{C}_{2} \mathrm{H}_{5} \mathrm{OH}\right)$ were used for determination of cation exchange capacity using the ammonium acetate displacement method. $0.1 \mathrm{M} \mathrm{NaOH}$ and $0.1 \mathrm{M} \mathrm{HNO}_{3}$ were used to adjust the $\mathrm{pH}$ of the solution while $0.01 \mathrm{M}$ of $\mathrm{KNO}_{3}$ was used as solution for point of zero charge determination. All chemical reagents were of analytical grade and were all supplied by Rochelle Chemicals.

\section{Apparatus}

Inductively Coupled Plasma- Optimal Emission Spectrometry (ICP-OES) iCAP (Thermo Scientific 7000 series) was used for metal ion analysis. Handheld XRF Olympus Delta Premium-50 kV was used for elemental composition analysis of both raw and activated biochar. A Malvern Mastersizer 300E - Hydro laser particle analyser was used for particle size analysis while the proximate analysis was done using Leco TGA 701 Thermo-Gravimetric Analyser. Functional group characterization was done using the Raman Spectrometer (Horiba Scientific). VWR Incubating shaker was used for conducting the batch adsorption experiments and the Drawell DW-XRD-Y3000 was used for mineral identification.

\section{Cation Exchange Capacity (CEC)}

About $0.20 \mathrm{~g}$ of biochar was leached five times with $20 \mathrm{~mL}$ of deionized water to reduce any interference with soluble salts. Then, the biochar was leached with $20 \mathrm{~mL}$ of $1 \mathrm{M}$ sodium acetate five times to dissolve sodium ions on the exchangeable sites. After that, the sample was washed with $20 \mathrm{~mL}$ of ethanol five times to remove the excess $\mathrm{Na}^{+}$. Afterwards, the $\mathrm{Na}^{+}$on the exchangeable sites of the biochar was displaced by $20 \mathrm{~mL}$ of 1 $\mathrm{M}$ ammonium acetate ( $\mathrm{pH}$ 7) five times, and the CEC of the biochar was calculated from the $\mathrm{Na}^{+}$displaced by $\mathrm{NH}_{4}^{+}$using Equation 1.

$$
C E C=\frac{C_{N a} \times V}{M M_{N a} \times M_{a d}}
$$

Where, CEC is the Cation Exchange Capacity in meq/100g of adsorbent, $\mathrm{C}_{\mathrm{Na}}$ is the concentration of $\mathrm{Na}^{+}$in $\mathrm{mg} / \mathrm{L}, \mathrm{V}$ is the volume of solution in $\mathrm{mL}, \mathrm{MM}_{\mathrm{Na}}$ is the molar mass of $\mathrm{Na}$ in $\mathrm{g} / \mathrm{mol}$ and $\mathrm{M}_{\mathrm{ad}}$ is the mass of the adsorbent used in $\mathrm{g}$.

\section{Point of Zero Charge $\left(\mathrm{pH}_{\mathrm{zc}}\right)$}

The point of zero charge for morula biochar was determined by adding $0.1 \mathrm{~g}$ of biochar to a series of $100 \mathrm{~mL}$ conical flasks; 5 flasks containing $0.01 \mathrm{M}$ of $\mathrm{KNO}_{3}$ and 5 flasks containing distilled water. The $\mathrm{pH}$ of both solutions was varied from 2.5 to 10.5 with increments of 2.0 using either $0.1 \mathrm{M}$
$\mathrm{NaOH}$ or $0.1 \mathrm{M} \mathrm{HNO}_{3}$. The flasks were then placed in a mechanical shaker at room temperature and pressure and rotated for 60 minutes at $120 \mathrm{rpm}$. The $\mathrm{pH}$ values of the suspensions were then measured. The $\mathrm{pH}$ of the suspension was represented as a function of the initial solution $\mathrm{pH}$. The initial $\mathrm{pH}$ of the solution $\left(\mathrm{pH}_{\mathrm{i}}\right)$ was plotted against the difference between the initial and final $\mathrm{pH}$ values $\left(\Delta \mathrm{pH}=\mathrm{pH}_{\mathrm{i}}-\right.$ $\mathrm{pH}_{\mathrm{f}}$ ) from which the $\mathrm{pHzc}$ was estimated at $\mathrm{pH}_{\mathrm{i}}$ where the graph cuts the $\mathrm{x}$-axis at $\Delta \mathrm{pH}=0$.

\section{Activation of the Biochar}

Chemical activation was be done using hydrochloric acid $(\mathrm{HCl})$. The sample was divided into two $50 \mathrm{~g}$ samples for the process. The ratio of impregnation was $1 \mathrm{~g}$ of sample to $20 \mathrm{~mL}$ acid (Hayashi et al., 2000). $50 \mathrm{~g}$ of char was added to $1000 \mathrm{~mL}$ of $2 \mathrm{M} \mathrm{HCl}$ in water and an overhead stirrer was used at 200 rpm for $2 \mathrm{~h}$ for proper mixing then heated at $110^{\circ} \mathrm{C}$ for $4 \mathrm{~h}$. After the mixture was cooled, it was then filtered with $6 \mu \mathrm{m}$ filter papers. To remove the acid, the filtered sample was washed first with distilled water and stirred at $150 \mathrm{rpm}$ for 30 min for proper washing then filtered again. The $\mathrm{pH}$ of the filtrate was observed to be 2.65 which showed that the acid was not washed off. Thus, the sample was soaked in $2 \% \mathrm{NaHCO}_{3}$ till any residual acid left has been removed and $\mathrm{pH}$ was tested again to be 8.42 . Lastly, the char was washed with deionized water until the $\mathrm{pH}$ was stable around 5.85 (initial $\mathrm{pH}$ of char). Then the sample was washed with distilled water again to remove any base left. The activated biochar was the filtered again and left to dry overnight.

\section{Adsorption Experiments}

Different adsorbent dosages were used for the two different adsorbate solutions for both raw and activated biochar. 1.0 $5.0 \mathrm{~g}$ of biochar was added to different $100 \mathrm{ml}$ solutions of the coal wash water of higher metal ion concentrations and $0.2-$ $1.0 \mathrm{~g}$ of biochar was used for lower metal concentrations. The solution was then agitated at $25^{\circ} \mathrm{C}$ and $150 \mathrm{rpm}$ for $60 \mathrm{~min}$ using VWR incubating shaker. After shaking, the solutions were then filtered using membrane filters of pore size $0.45 \mu \mathrm{m}$ and the filtrate was acidified with 1 drop of nitric acid to preserve the sample then stored at room temperature awaiting metal analysis using ICP-OES. After metal analysis, the removal percentages were calculated using the Equation 2 .

$$
\% \text { Removal }=\frac{C_{o}-C_{f}}{C_{o}} \times 100 \%
$$

Where $\mathrm{C}_{\mathrm{o}}$ and $\mathrm{C}_{\mathrm{f}}$ are the concentrations of metal ions before and after adsorption in $\mathrm{mg} / \mathrm{L}$

\section{RESULTS AND DISCUSSION}

\section{Characterization of the Adsorbent}

\section{Mineral Composition (XRD)}

In a diffractometric pattern, sharp peaks represent crystalline phases while amorphous phases are shown by broad peaks (Kapur and Mondal, 2014; Lekgoba et al., 2020). Figure 1 shows that morula biochar is amorphous and both activated and raw fly ash are showing a similar diffractometric pattern which suggests that the activation of morula char did not effect 


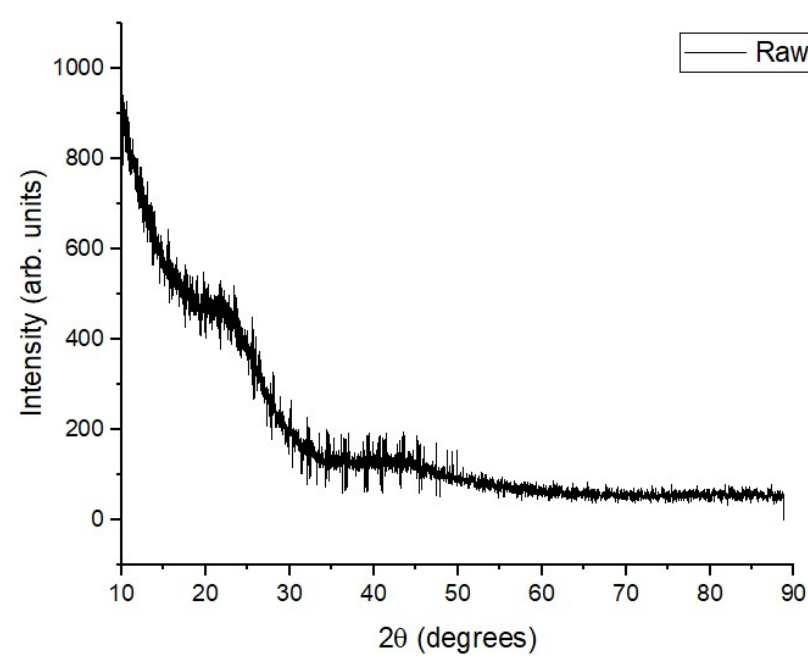

(a)

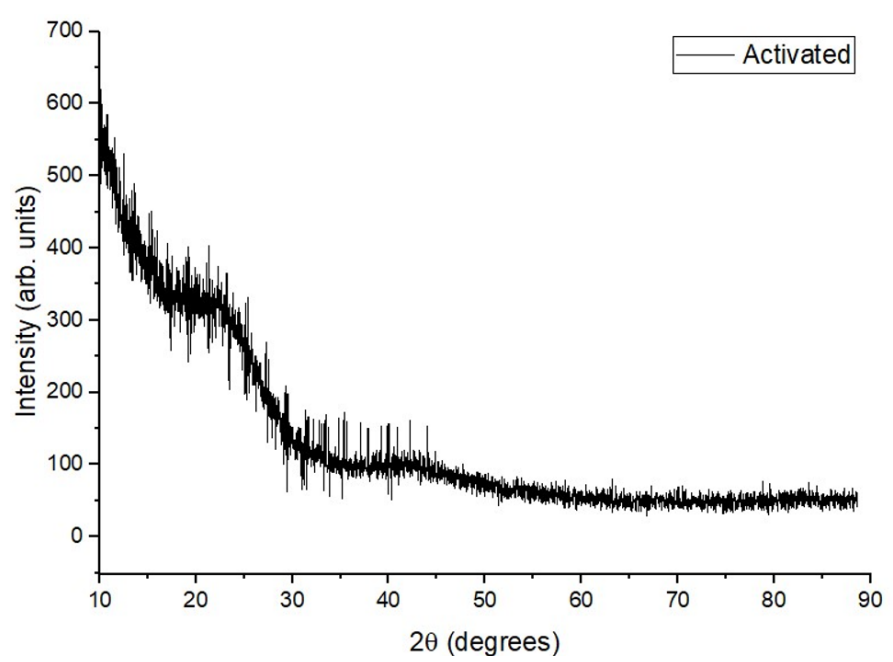

(b)

Figure 1. (a) Diffractometric pattern of Raw Char (b) Diffractometric pattern of Activated Char

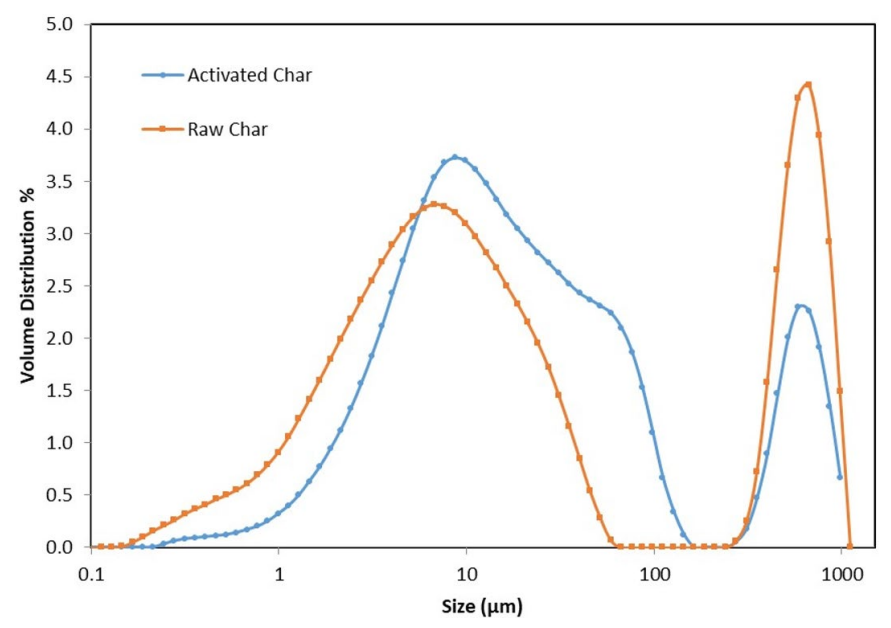

(a)

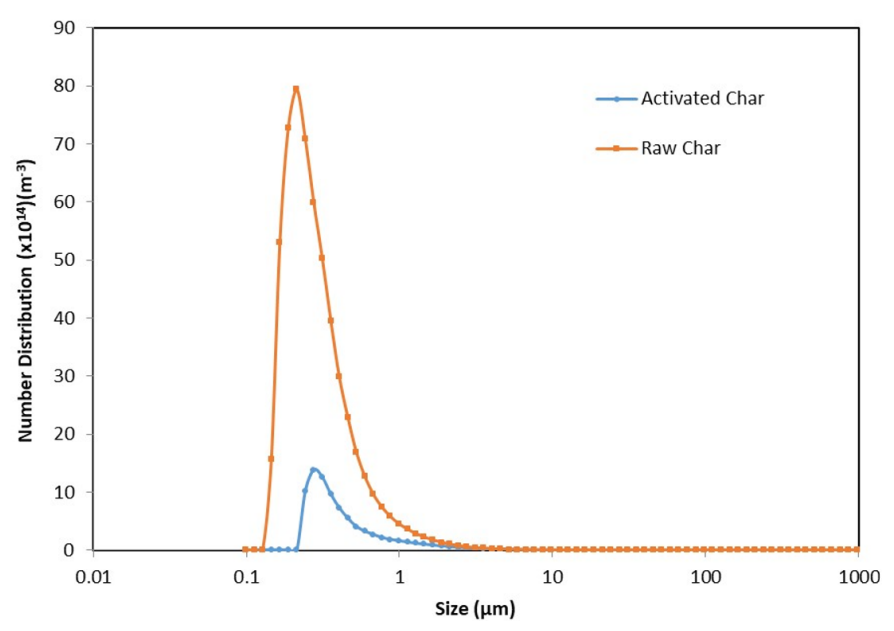

(b)

Figure 2. (a) Particle size analysis of Morula based Biochar - Volume Distribution (b) Particle size analysis of Morula based Biochar - Number Distribution

any changes in the diffraction pattern. The bump noticed between 20 and $30^{\circ} \sim 2 \theta$ may be attributed to the scattering of $\mathrm{x}$-rays which normally presents three or fewer halos in the diffractometric patterns (Bates et al., 2006).

\section{Proximate Analysis (TGA)}

Biochar was analyzed for moisture content, volatile matter and ash content. The main interest was the amount of fixed carbon in the char, it has been found that good chars have fixed carbon of over $75 \%$. Moreover, it was found that the increase in pyrolytic temperature also increases the development of good char with the highest fixed carbon. From the Table 1, fixed carbon was found to be 80 and $84 \%$ at $600^{\circ} \mathrm{C}$ of pyrolysis temperature. This is because at higher temperatures the amount of lignin in the biomass is responsible for the formation of char. Lignin is a highly rigid substance which is resistant to thermal degradation, therefore can only be decomposed at higher temperatures, hence the higher the pyrolysis temperature the more the lignin is broken down to form char (Hernandez-Mena et al., 2014). The fixed carbon
Table 1. Proximate analysis of Morula based biochar

\begin{tabular}{cc}
\hline Name & Morula biochar \\
\hline Moisture (\%) & 4.62 \\
\hline Volatile (\%) & 12.39 \\
\hline Volatile dry (\%) & 13.26 \\
\hline Ash (\%) & 2.47 \\
\hline Ash dry (\%) & 2.59 \\
\hline Fixed Carbon (\%) & 80.52 \\
\hline Fixed Carbon dry (\%) & 84.15 \\
\hline
\end{tabular}

produced is due to the decomposition of the hydroxyl functional groups forming hydrogen and oxygen.

\section{Particle Size Distribution (PSD)}

The particle size volume and number distributions of both activated and raw biochars were determined and are shown in Figure 2. The bimodal curves are typical of an agglomeration process and show that particle agglomeration occurred during pyrolysis (Sithole et al., 2015). For raw biochar it was found that finer particles were concentrated at around $5.92 \mu \mathrm{m}$ while larger particles ranged from 272 and $666 \mu \mathrm{m}$ (Figure 2) and for 
Table 2. Elemental composition from XRF

\begin{tabular}{ccccc}
\hline \multirow{2}{*}{ Elemental composition (wt.\%) } & \multicolumn{2}{c}{ Raw biochar } & \multicolumn{2}{c}{ Activated biochar } \\
\cline { 2 - 5 } & Before & After & Before & \multicolumn{2}{c}{ After } \\
\hline $\mathrm{Al}$ & 33.56 & 28.65 & 12.26 & 14.06 \\
\hline $\mathrm{Si}$ & 3.78 & 7.51 & 5.44 & 0.71 \\
\hline $\mathrm{P}$ & 1.37 & 2.44 & 0.94 & 2.61 \\
\hline $\mathrm{S}$ & 1.52 & 2.69 & 1.52 & 50.13 \\
\hline $\mathrm{Cl}$ & 0.32 & 0.65 & 60.82 & 0.58 \\
\hline $\mathrm{K}$ & 38.62 & 14.67 & 0.92 & 6.51 \\
\hline $\mathrm{Ca}$ & 16.76 & 10.46 & 7.53 & 0.98 \\
\hline $\mathrm{Cr}$ & 0.85 & 0.79 & 0.97 & 1.28 \\
\hline $\mathrm{Mn}$ & 1.12 & 1.19 & 1.34 & 13.52 \\
\hline $\mathrm{Fe}$ & 1.70 & 24.49 & 7.50 & 0.00 \\
\hline $\mathrm{Ni}$ & 0.00 & 0.55 & 0.00 & 0.34 \\
\hline $\mathrm{Cu}$ & 0.26 & 0.28 & 0.65 & 0.27 \\
\hline $\mathrm{Zn}$ & 0.08 & 5.59 & 0.04 & \\
\hline $\mathrm{Ads}$ & & & & \\
\hline
\end{tabular}

NB: Before $=$ Before Adsorption, After $=$ After Adsorption

activated char the volume distribution shows that the finer particles were concentrated around $7.64 \mu \mathrm{m}$ while larger particles ranged from $310-586 \mu \mathrm{m}$. From these two figures, it is seen that there is a higher proportion of larger sized particles in raw char as compared to activated char based on the volume distribution. This is an indication that activated char had few larger particles than raw char which might be due to size reduction during agitation when mixing with the acid. Figure 2 shows that both chars had a higher number of finer particles of less than $1 \mu \mathrm{m}$ with activated char having a modal size of $0.276 \mu \mathrm{m}$ and raw char of $0.214 \mu \mathrm{m}$. The laser diffraction technique enables the calculation of the external surface area of the adsorbent particles by transforming the volume distribution to a number distribution and the surface area is thus calculated from the second moment $\left(\mathrm{m}_{2}\right.$ is equal to external surface area) (Ntuli and Lewis, 2009). It was found that the external surface area of activated char was $6.028 \mathrm{~m}^{2} / \mathrm{g}$ and $11.83 \mathrm{~m}^{2} / \mathrm{g}$ for raw char. Acid activation increases the surface functional groups in an adsorbent while decreasing the surface area hence the lower external surface area observed for activated char.

\section{Chemical Composition (XRF)}

Results from XRF shows that several metal elements are available on the biochar surface as presented in Table 2 . Comparing the effect of acid activation of the biochar on the composition of the elements, it shows that $\mathrm{Al}$, Ca and $\mathrm{K}$ reduced drastically. Since these are alkali metals, during acid activation with $\mathrm{HCl}$ the metal ions formed metal chlorides due to reaction with the acid. It was also found that $\mathrm{Cl}$ ions increased from $0.32 \%$ to $60.82 \%$ after activation which was expected due to addition of $\mathrm{Cl}$ ions to the char during activation. During adsorption of the raw biochar it was found that the concentration of the elements of interest for adsorption, Fe, Ni and $\mathrm{Zn}$ increased. Fe increased from $1.7 \%$ to $24.49 \%$, Zn from $0.08 \%$ to $5.59 \%$ and Ni from 0 to $0.55 \%$. This shows that these elements were adsorbed on the surface of the char, with Fe having the highest adsorption percentages. Other elements which experienced a change in concentration, include $\mathrm{Ca}$ and $\mathrm{Al}$ which dropped while $\mathrm{S}$ increased from 1.52\% to $2.69 \%$, and this may be attributed to the presence of sulphates in water which might have been adsorbed too.

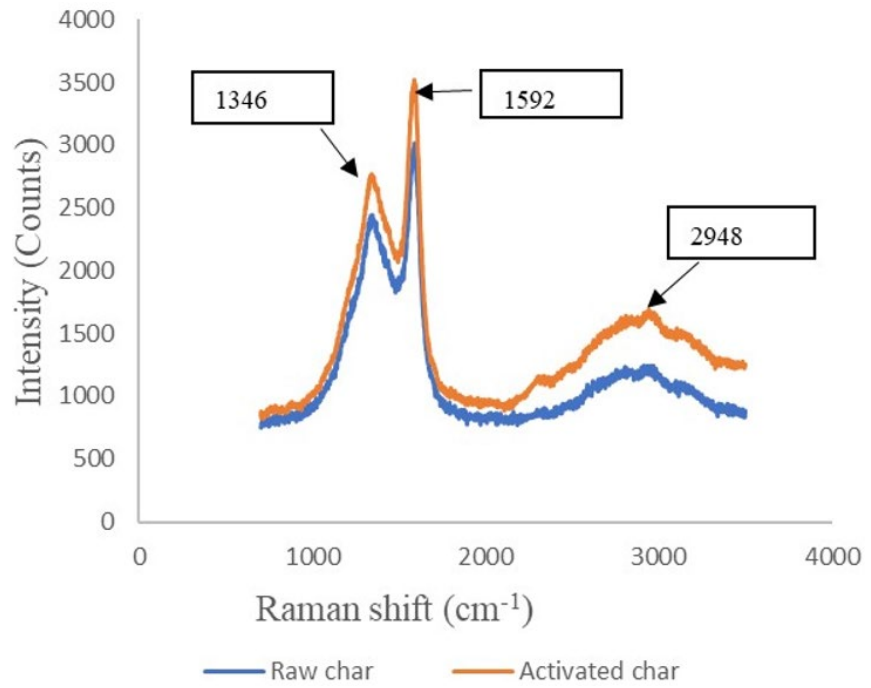

Figure 3. Raman spectrum of raw and activated biochar

\section{Functional Groups (Raman Spectroscopy)}

One of the most important characteristics of an adsorbent is the surface functional groups, this was characterized using Raman spectrometer. Figure 3 shows the available surface function groups in both raw and activated biochars. The spectrum indicates the presence of nitro group $\mathrm{N}=\mathrm{O}\left(1346 \mathrm{~cm}^{-}\right.$ $\left.{ }^{1}\right)$, aromatic ring $\mathrm{C}=\mathrm{C}\left(1592 \mathrm{~cm}^{-1}\right)$ and carboxylic acid group $\mathrm{O}$ $\mathrm{H}\left(2948 \mathrm{~cm}^{-1}\right)$. The aromatic peaks are normally present in chars which are pyrolyzed at higher temperatures of up to $400^{\circ} \mathrm{C}$. This is because at lower temperatures of around 200 and $300^{\circ} \mathrm{C}$ only softer carbon components such as $\mathrm{O}-\mathrm{H}$ functional groups are present. As the temperature is increased these groups break down leaving the hard carbon components which form stable chars with $\mathrm{C}=\mathrm{C}$ and $\mathrm{C}=\mathrm{O}$ bonds. This trend was observed by (Chen and Chen, 2009) and this explains the strong peak at $1592 \mathrm{~cm}^{-1}$ and a weaker peak at $2948 \mathrm{~cm}^{-1}$ since this biochar was carbonized at $600{ }^{\circ} \mathrm{C}$. These groups are essential for increasing the oxygenated functional groups which are good adsorptive sites for metal ions. Both activated and raw chars depicted the same functional groups, with activated char having higher intensities for the peaks identified. This is because chemical activation increases the 


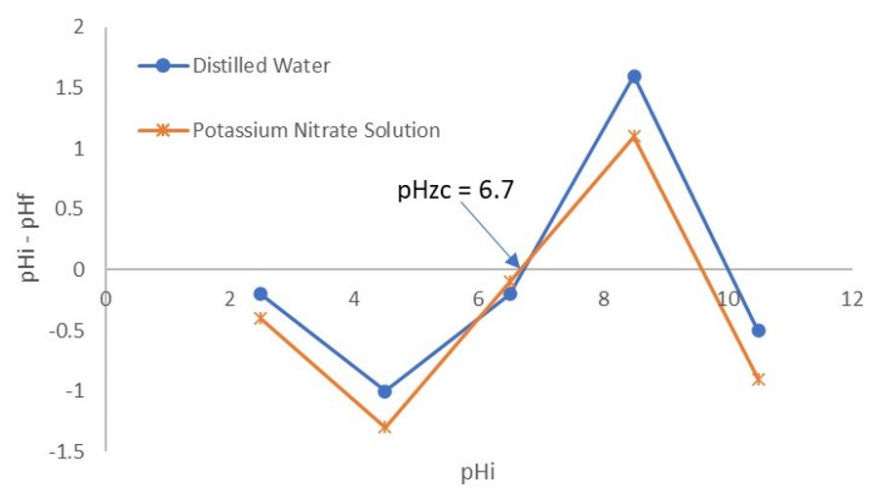

Figure 4. Point of Zero Charge for Morula based Biochar

acidic functional groups of the biochar which act as good adsorptive sites (Enaime et al., 2020).

\section{Cation Exchange Capacity}

It was found the activated biochar had a higher CEC of $33.257 \mathrm{meq} / 100 \mathrm{~g}$ than the raw biochar with $0.0962 \mathrm{meq} / 100 \mathrm{~g}$ as expected. This can be attributed to the fact that chemical activation increases porosity as well as the internal surface area of the chars hence the higher exchange of the Na cation. Thus, this enables adsorption of the cations into the exchangeable sites of the char. Increased CEC for acid activations was also observed by (Doğan and Alkan, 2003) on perlite biochars. The increase of CEC after activation process was also a result of the increase in oxygenated functional nitro group $\left(1346 \mathrm{~cm}^{-1}\right)$ which means an increase in negative charges influences the uptake of $\mathrm{Na}$ ions (Nartey and Zhao, 2014).

\section{Point of Zero Charge}

The surface charge of an adsorbent is known to be a function of the solution $\mathrm{pH}$ and the point at which the net charge of the adsorbent is zero is known as the point of zero charge $\left(\mathrm{pH}_{\mathrm{zc}}\right)$ (Demirbas et al., 2009; Freitas et al., 2017). When the $\mathrm{pHzc}$ is lower than the solution $\mathrm{pH}$, the surface charge of the adsorbent is then considered to be negative because as the surface charge decreases, the $\mathrm{pH}$ increases and this implies that metal adsorption will be higher (Chen et al., 1996). The $\mathrm{pH}_{\mathrm{zc}}$ of morula biochar was found to be 6.7 as shown in Figure 4 and this suggests that at $\mathrm{pH}$ 's below the $\mathrm{pHzc}$ the surface of the biochar is predominated by positive charges while at those greater than $\mathrm{pH}_{\mathrm{zc}}$ it is predominated by negative charges (Mohan and Gandhimathi, 2009). According to Kalembkiewicz and Sočo (2013), most metal ions start precipitating or forming metal hydroxide at pH's above 10 hence the $\mathrm{pHzc}_{\mathrm{zc}}$ was considered until $\mathrm{pH} 8.5$ for this study. The presence of another $\mathrm{pH}_{\mathrm{zc}}$ at $\mathrm{pH}$ values greater than 8.5 is due to heterogeneity and presence of both carboxylic and nitro groups on the surface of the biochar.

\section{Coal Wash Water Characterization}

The coal wash water used for this study was characterised to determine the physicochemical characteristics of the water. The coal wash water samples before and after adsorption were analysed using standard methods as outlined in the Standard Methods for the Examination of Water and Wastewater (Eaton et al., 1998). The concentration levels of heavy metals, anions
Table 3. Coal wash water characterization

\begin{tabular}{cc}
\hline Heavy Metal & Concentration (ppm) \\
\hline Iron & 649.47 \\
\hline Zinc & 661.24 \\
\hline Nickel & 435.51 \\
\hline Copper & $\mathrm{ND}$ \\
\hline Arsenic & $\mathrm{ND}$ \\
\hline Lead & $\mathrm{ND}$ \\
\hline Manganese & 261.795 \\
\hline Anions & Concentration (ppm) \\
\hline Chloride & 102.790 \\
\hline Nitrate & ND \\
\hline Bromide & $\mathrm{ND}$ \\
\hline Phosphate & 2.026 \\
\hline Fluoride & $\mathrm{ND}$ \\
\hline Sulphate & 8.38 \\
\hline & Physical Parameters \\
\hline pH & $1173 \mu \mathrm{cm}$ \\
\hline Conductivity & $587 \mathrm{ppm}$ \\
\hline TDS & $3.85 \mathrm{ppm}$ \\
\hline Dissolved Oxygen & \\
\hline
\end{tabular}

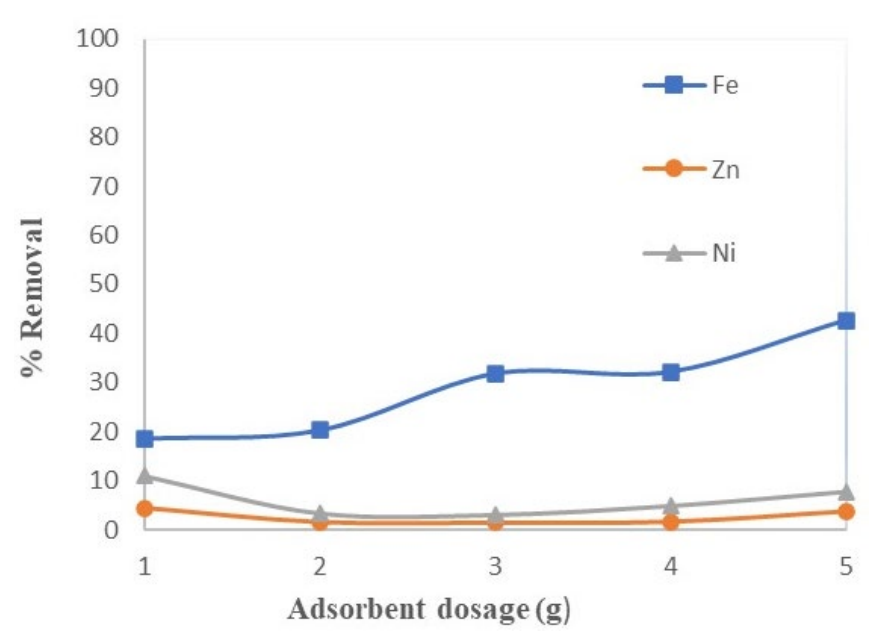

Figure 5. Percentage removals of $\mathrm{Fe}, \mathrm{Zn}$ and $\mathrm{Ni}$ at concentrations of $>600 \mathrm{mg} / \mathrm{L}$ for Fe and $\mathrm{Zn}$ and $\mathrm{Ni}$ at $>400 \mathrm{mg} / \mathrm{L}$ using raw biochar at a $\mathrm{pH}$ of 5.8

and the physical parameters of coal wash water are presented in Table 3.

\section{Effect of Adsorbent Dosage at Different Metal Ion Concentrations}

\section{Raw Biochar}

From Figure 5, it was found that Fe percentage removals increased with increase in adsorbent dosage, with $18.56 \%$ using $1 \mathrm{~g} / 100 \mathrm{~mL}$ and $42.64 \%$ using $5 \mathrm{~g} / 100 \mathrm{ml}$ of biochar. $\mathrm{Zn}$ and Ni portrayed a similar trend, they had the highest removals of $4.3 \%$ and $11.05 \%$ respectively with $1 \mathrm{~g} / 100 \mathrm{~mL}$ and decreased as the dosage increased. However, there was a marginal increase in removal when using $5 \mathrm{~g} / 100 \mathrm{~mL}$. From Figure 5, it is evident that raw biochar removes these metal ions effectively at higher dosages. When using ion concentrations of $60 \mathrm{mg} / \mathrm{L}$ for Fe and $\mathrm{Zn}$ and $40 \mathrm{mg} / \mathrm{L}$ of $\mathrm{Ni}$ at char dosages of less than $1 \mathrm{~g}$, it was observed that all the three ions had the highest removals compared to the previous experiment as indicated in Figure 6. 


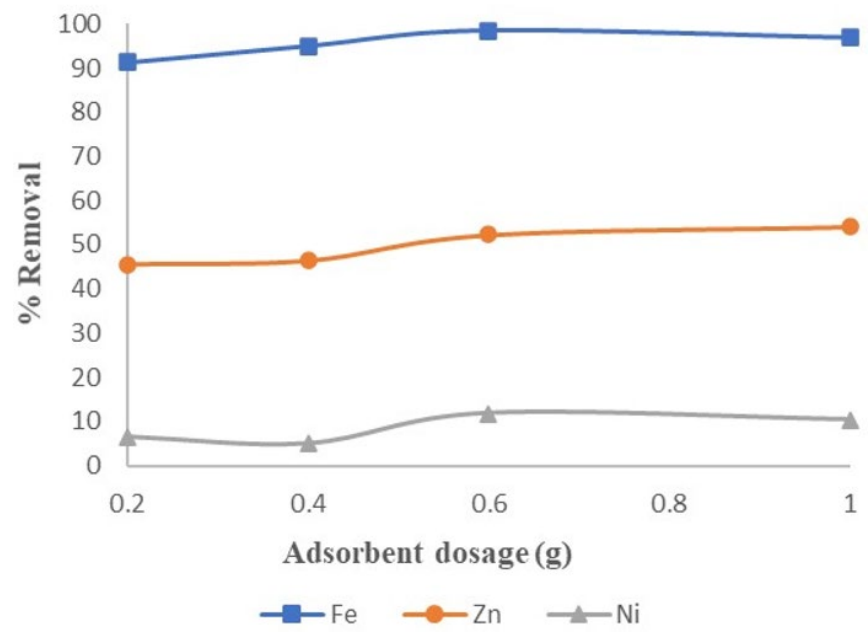

Figure 6. Percentage removals of $\mathrm{Fe}, \mathrm{Zn}$ and $\mathrm{Ni}$ at concentrations of $60 \mathrm{mg} / \mathrm{L}$ for $\mathrm{Fe}$ and $\mathrm{Zn}$ and $\mathrm{Ni}$ at $40 \mathrm{mg} / \mathrm{L}$ using raw biochar at a $\mathrm{pH}$ of 5.8

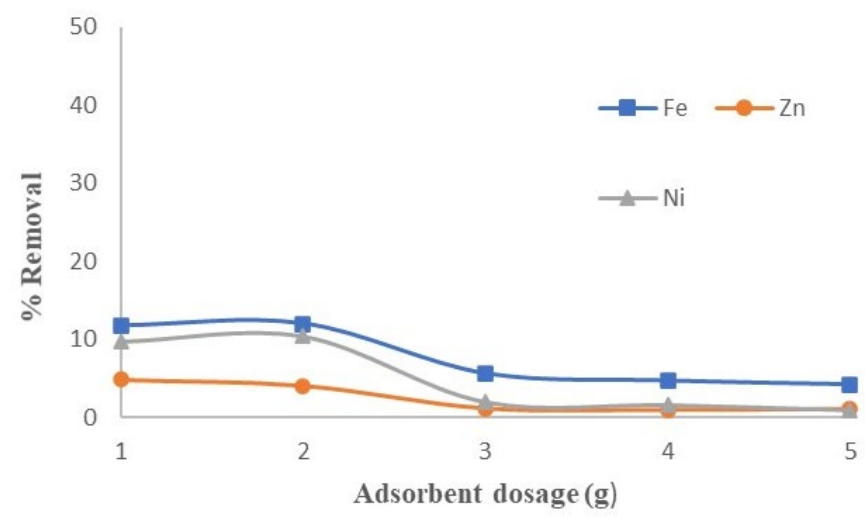

Figure 7. Percentage removals of $\mathrm{Fe}, \mathrm{Zn}$ and $\mathrm{Ni}$ at concentrations of $>600 \mathrm{mg} / \mathrm{L}$ for $\mathrm{Fe}$ and $\mathrm{Zn}$ and $\mathrm{Ni}$ at $>400 \mathrm{mg} / \mathrm{L}$ using activated biochar at a $\mathrm{pH}$ of 5.8

\section{Activated Biochar}

When using activated biochar (Figure 7), all the ions had a similar trend: as the dosage increased the removal percentages dropped until they reached a constant point. Fe was preferentially removed using both raw and activated biochar and this might have been due to the ionic radius of these ions. The removal percentages were recorded as follows $\mathrm{Fe}>\mathrm{Ni}>\mathrm{Zn}$ and this corresponded to the ionic radii of these metal ions which are $0.7 \AA<0.72 \AA<0.74 \AA$ respectively. It is known that the smaller the ionic radius the higher the adsorption capacity of the cation because the ion travels faster to adsorptive sites than the one with a large ionic radius (Gao et al., 2009). Figure 8 shows that activated biochar works best at lower dosages. The overall lower removal percentages were attributed to high metal ion concentrations which might have led to saturation of adsorptive sites hence less ions adhered to the surface of the char. Realizing this trend, another experiment was done using lower dosages and lower metal ion concentrations.

Fe had removals of greater than $90 \%$ for both raw and activated biochar, $\mathrm{Zn}$ recorded more than $50 \%$ removals while $\mathrm{Ni}$ was the only one which had the lowest removals of less than $20 \%$ for both chars. The higher removals were due to lower metal ion concentrations, hence more adsorptive sites but less

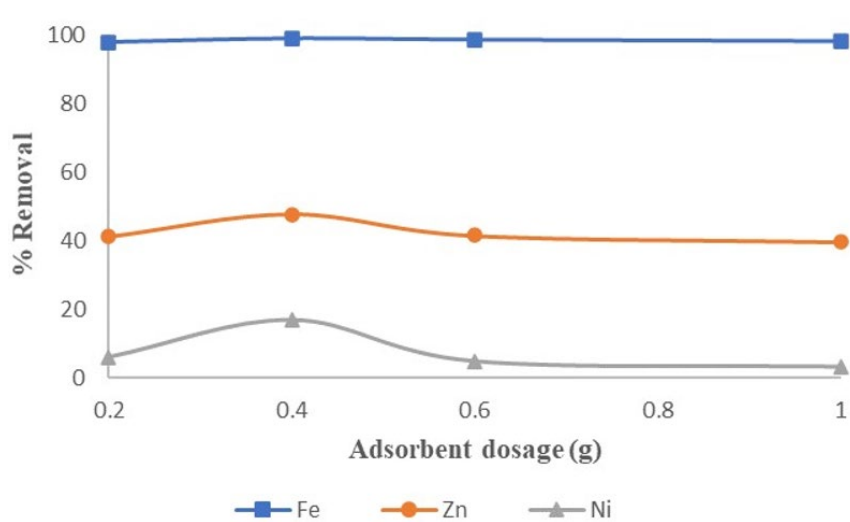

Figure 8. Percentage removals of $\mathrm{Fe}, \mathrm{Zn}$ and $\mathrm{Ni}$ at concentrations of $60 \mathrm{mg} / \mathrm{L}$ for $\mathrm{Fe}$ and $\mathrm{Zn}$ and $\mathrm{Ni}$ at $40 \mathrm{mg} / \mathrm{L}$ using activated biochar at a $\mathrm{pH}$ of 5.8

heavy metal ions to adhere to the surface of the char. Several observations were made on the mechanisms of adsorption that might have occurred. For instance, it was postulated that cation exchange might have occurred during removal of heavy metals. Metal ions such as $\mathrm{K}^{+}$and $\mathrm{Ca}^{2+}$ were present in higher amounts on chars before adsorption. However, they decreased after adsorption as illustrated in Table 2, which shows that some have been removed from the char surface into the adsorbate, this trend was also observed by Yang et al. (2019). Furthermore, the presence of oxygenated functional groups on the surface of char might have led to electrostatic attraction between the metal ions and negatively charged oxygenated functional groups which led to ions being removed from the wastewater on to the surface of the biochar. In addition, the higher cation exchange capacity of activated char also contributed to the adsorption process (Xie et al., 2017).

\section{CONCLUSION}

Pyrolyzed morula shells can be used to remove heavy metals in wastewater. Acid modification of biochar increased its CEC and it was found that the point of zero charge for morula based biochar was 6.7 which is well lower that the $\mathrm{pH}$ of the solution hence making it act as a negative surface. Morula biochar presented an amorphous phase in the mineralogy study, and it also showed a higher fixed carbon content of more than $75 \%$ indicating that it is good for adsorption. Biochar had $\mathrm{C}=\mathrm{C}, \mathrm{N}=\mathrm{O}$ and $\mathrm{O}-\mathrm{H}$ surface functional groups which were responsible for the adsorption process by electrostatic attraction with the metal ions. The external surface area of raw and activated char was found to be 11.832 and $6.0286 \mathrm{~m}^{2} / \mathrm{g}$ respectively. Elemental composition revealed the presence of several metal ions including $\mathrm{K}$ and $\mathrm{Ca}$ which played a role in cation exchange. It was noted that both raw and activated biochar removed Fe better than Zn and Ni mainly because of the ionic radius of the metal ions, with Fe having the smallest radius followed by Nithen $\mathrm{Zn}$. Low dosages had a higher removal capacity at concentrations of $40-60 \mathrm{mg} / \mathrm{L}$ while higher dosages had lower removal capacities at concentrations of $400-600 \mathrm{mg} / \mathrm{L}$. It can be concluded that morula shells could be used as a low-cost adsorbent in removing contaminants in wastewater. 
Author contributions: All authors were involved in all the stages of this study while preparing the final version. They all agree with the results and conclusions.

Funding: No external funding is received for this article.

Declaration of interest: The authors declare that they have no competing interests.

Ethics approval and consent to participate: Not applicable. Availability of data and materials: All data generated or analyzed during this study are available for sharing when appropriate request is directed to corresponding author.

\section{REFERENCES}

Abdullah, E. J. (2013). Evaluation of surface water quality indices for heavy metals of Diyala River-Iraq. Journal of Natural Sciences Research, 3(8), 63-70.

Ali, I. and Gupta, V. K. (2007). Advances in water treatment by adsorption technology. Nature Protocols, 1(6), 2661-2667. https://doi.org/10.1038/nprot.2006.370

Bates, S., Zografi, G., Engers, D., Morris, K., Crowley, K. and Newman, A. (2006). Analysis of amorphous and nanocrystalline solids from their X-ray diffraction patterns. Pharmaceutical Research, 23(10), 2333-2349. https://doi.org/10.1007/s11095-006-9086-2

Cao, Q., Huang, Z., Liu, S. and Wu, Y. (2019). Potential of Punica granatum biochar to adsorb Cu ( II ) in soil. Nature, 9(Ii), 1-13. https://doi.org/10.1038/s41598-019-46983-2

Chen, B. and Chen, Z. (2009). Sorption of naphthalene and 1naphthol by biochars of orange peels with different pyrolytic temperatures. Chemosphere, 76, 127-133. https://doi.org/10.1016/j.chemosphere.2009.02.004

Chen, J., Yiacoumi, S. and Blaydes, T. G. (1996). Equilibrium and kinetic studies of copper adsorption by activated carbon. Separations Technology, 6(2), 133-146. https://doi.org/10.1016/0956-9618(96)00146-4

Clesceri, L. S., Greenberg, A. E. and Eaton, A. D. (1998). Standard methods for the examination of water and wastewater (20th Ed.). Washington, DC: American Public Health Association.

Demirbas, E., Dizge, N., Sulak, M. T. and Kobya, M. (2009). Adsorption kinetics and equilibrium of copper from aqueous solutions using hazelnut shell activated carbon. Chemical Engineering Journal, 148(2-3), 480-487. https://doi.org/10.1016/j.cej.2008.09.027

Doğan, M. and Alkan, M. (2003). Removal of methyl violet from aqueous solution by perlite. Journal of Colloid and Interface Science, 267(1), 32-41. https://doi.org/10.1016/S00219797(03)00579-4

Enaime, G., Baçaoui, A., Yaacoubi, A. and Lübken, M. (2020). Biochar for wastewater treatment-conversion technologies and applications. Applied Sciences (Switzerland), 10(10), 129. https://doi.org/10.3390/app10103492

Freitas, E. D., Carmo, A. C. R., Neto, A. F. A. and Vieira, M. G. A. (2017). Binary adsorption of silver and copper on Verdelodo bentonite: Kinetic and equilibrium study. Applied Clay Science, 137, 69-76. https://doi.org/10.1016/j.clay.2016.12. 016
Gao, Z., Bandosz, T.J., Zhao, Z., Han, M. and Qui, J. (2009). Investigation of factors affecting adsorption of transition metals on oxidized carbon nanotubes. Journal of Hazardous Materials, 167(1-3), 357-365. https://doi.org/10.1016/ j.jhazmat.2009.01.050

Hayashi, J., Kazehaya, A., Muroyama, K. and Watkinson, A. P. (2000). Preparation of activated carbon from lignin by chemical activation. Carbon, 38(13), 1873-1878. https://doi.org/10.1016/S0008-6223(00)00027-0

Hernandez-Mena, L. E., Pecora, A. A. B. and Beraldo, A. L. (2014). Slow pyrolysis of bamboo biomass: Analysis of biochar properties. Chemical Engineering Transactions, 37, 115-120. https://doi.org/10.3303/CET1437020

Kalembkiewicz, J. and Soc, E. (2013). Adsorption of nickel ( II ) and copper ( II ) ions from aqueous solution by coal fly ash. Journal of Environmental Chemical Engineering, 1, 581-588. https://doi.org/10.1016/j.jece.2013.06.029

Kapur, M. and Mondal, M. K. (2014). Competitive sorption of $\mathrm{Cu}$ ( II ) and Ni ( II ) ions from aqueous solutions: Kinetics, thermodynamics and desorption studies. Journal of the Taiwan Institute of Chemical Engineers, 45(4), 1803-1813. https://doi.org/10.1016/j.jtice.2014.02.022

Lekgoba, T., Ntuli, F. and Falayi, T. (2020). Application of coal fly ash for treatment of wastewater containing a binary mixture of copper and nickel. Journal of Water Process Engineering, 40(November 2020), 101822. https://doi.org/10.1016/j.jwpe.2020.101822

Malaviya, P. and Singh, A. (2011). Physicochemical technologies for remediation of chromium-containing waters and wastewaters. Critical Reviews in Environmental Science and Technology, 41(12), 1111-1172. https://doi.org/10.1080/10643380903392817

Mohan, S. and Gandhimathi, R. (2009). Removal of heavy metal ions from municipal solid waste leachate using coal fly ash as an adsorbent. Journal of Hazardous Materials, 169, 351-359. https://doi.org/10.1016/j.jhazmat.2009.03.104

Nartey, O. D. and Zhao, B. (2014). Biochar preparation, characterization, and adsorptive capacity and its effect on bioavailability of contaminants: An overview. Advances in Materials Science and Engineering, 2014, 715398. https://doi.org/10.1155/2014/715398

Ntuli, F. and Lewis, A. E. (2009). Kinetic modelling of nickel powder precipitation by high-pressure hydrogen reduction. Chemical Engineering Science, 64(9), 2202-2215. https://doi.org/10.1016/j.ces.2009.01.026

Sen, T. K. and Gomez, D. (2011). Adsorption of zinc ( Zn $2+$ ) from aqueous solution on natural bentonite. DES, 267(2-3), 286-294. https://doi.org/10.1016/j.desal.2010.09.041

Sharma, S. and Bhattacharya, A. (2017). Drinking water contamination and treatment techniques. Applied Water Science, 7(3), 1043-1067. https://doi.org/10.1007/s13201016-0455-7

Sithole, T., Ntuli, F. and Falayi, T. (2015). The removal of Ni \& $\mathrm{Cu}$ from a mixed metal system using Sodium borohydride as a reducing agent. South African Journal of Chemical Engineering, 20(1), 16-29. 
Wynberg, R., Cribbins, J., Lombard, C. and Mander, M. (2002). Knowledge on Sclerocarya birrea subsp. caffra with emphasis on its importance as a non-timber forest product in South and southern Africa: A Summary. South Africa Forestry Journal, 196(1), 67-77. https://doi.org/10.1080/ 20702620.2002.10434589

Xie, R., Jin, Y., Chen, Y. and Jiang, W. (2017). The importance of surface functional groups in the adsorption of copper onto walnut shell derived activated carbon. Water Science and Technology: A Journal of the International Association on Water Pollution Research, 76(11-12), 3022-3034. https://doi.org/10.2166/wst.2017.471
Yang, X., Wan, Y., Zhen, Y., He, F., Yu, Z., Huang, J., Wang, H., Ok, Y. S., Jiang, Y. and Gao, B. (2019). Surface functional groups of carbon-based adsorbents and their roles in the removal of heavy metals from aqueous solutions: A critical review. Chemical Engineering Journal, 366, 608-621. https://doi.org/10.1016/j.cej.2019.02.119 